\title{
Different Patterns of Bacterial Species and Antibiotic Susceptibility in Diabetic Foot Syndrome with and without Coexistent Ischemia
}

\author{
Rafał Małecki $\mathbb{D}^{1},{ }^{1}$ Kamil Klimas $\left(\mathbb{D},{ }^{1}\right.$ and Aleksandra Kujawa $\mathbb{D}^{2}$ \\ ${ }^{1}$ Department of Angiology, Systemic Hypertension and Diabetology, Wrocław Medical University, Borowska 213, \\ 50-556 Wroctaw, Poland \\ ${ }^{2}$ University Hospital of Jan Mikulicz-Radecki, Borowska 213, 50-556 Wrocław, Poland \\ Correspondence should be addressed to Rafał Małecki; rafal.malecki@umed.wroc.pl
}

Received 25 March 2021; Accepted 19 April 2021; Published 28 April 2021

Academic Editor: Agata Stanek

Copyright (C) 2021 Rafał Małecki et al. This is an open access article distributed under the Creative Commons Attribution License, which permits unrestricted use, distribution, and reproduction in any medium, provided the original work is properly cited.

\begin{abstract}
Aims. Infection in diabetic foot syndrome (DFS) represents serious medical problem, and the annual risk of DFS in diabetic patients is $2.5 \%$. More than half of the patients with DFS have symptoms of extremity ischemia (peripheral arterial disease (PAD)). The aim of the present study was to analyze the frequency of particular bacterial strains in people with DFS, analyze the impact of arterial ischemia on the occurrence of a given pathogen, and evaluate the antibacterial treatment based on the results of bacterial culture. Methods. The analysis included 844 bacterial strains obtained from 291 patients with DFS hospitalized in the Department of Angiology in years 2016-2019. Results. The most common isolates were Staphylococcus aureus, Enterococcus faecalis, Enterobacter cloacae, Pseudomonas aeruginosa, and Acinetobacter baumannii. Nearly $20 \%$ of the species were found to have at least one resistance mechanism. In patients with $\mathrm{PAD}$, Gram-negative species were isolated more commonly than in people without PAD. The most useful drugs in DFS in hospitalized patients are penicillins with beta-lactamase inhibitors, 3rd- to 5thgeneration cephalosporins (with many exceptions), carbapenems, aminoglycosides, and tigecycline. Conclusions. Bacterial strains isolated from ischemic DFS are more resistant to commonly used antibacterial agents, i.e., penicillins (including penicillins with beta-lactamase inhibitors), cephalosporins (except for the $4^{\text {th }}$ and $5^{\text {th }}$ generations), glycopeptides, and linezolid. When planning treatment of hospitalized patients with DFS, the presence of ischemia in DFS should always be taken into consideration. It determines the occurrence of particular bacterial species and the choice of antibacterial agent and may determine the rate of treatment success.
\end{abstract}

\section{Introduction}

Diabetes mellitus is a social disease with the prevalence more than $5 \%$ that exerts a heavy burden on the healthcare system. One of the most common chronic complications of diabetes mellitus is diabetic foot syndrome (DFS)-defined as an infection, ulceration, and/or destruction of the foot in patients with diabetic neuropathy or peripheral arterial disease (PAD). The estimated global prevalence of DFS is 6.3\% among patients with this disease [1]; it is also known that $20 \%$ of all diabetic patients require hospitalization because of DFS, and the annual risk of developing this complication is $2.5 \%$ [2].

One of the most serious problems faced by physicians treating patients with DFS is an introduction of appropriate empiric antibacterial therapy before the results of microbiological culture are collected and antibiogram is available. The aim of the present study was to analyze the frequency of particular bacterial strains in people with DFS, analyze the impact of arterial ischemia on the occurrence of a given pathogen, and evaluate the antibacterial treatment in this group of patients, taking into account the presence of PAD. 
TABLE 1: Number of particular bacterial isolates in all patients with diabetic foot syndrome.

\begin{tabular}{|c|c|c|}
\hline & Number of isolates & Percent \\
\hline Staphylococcus aureus & 211 & 25.00 \\
\hline Enterococcus faecalis & 96 & 11.37 \\
\hline Enterobacter cloacae & 66 & 7.82 \\
\hline Pseudomonas aeruginosa & 58 & 6.87 \\
\hline Acinetobacter baumannii & 54 & 6.40 \\
\hline Klebsiella pneumoniae & 50 & 5.92 \\
\hline Escherichia coli & 44 & 5.21 \\
\hline Proteus mirabilis & 31 & 3.67 \\
\hline Streptococcus agalactiae & 24 & 2.84 \\
\hline Proteus spp. & 19 & 2.25 \\
\hline Enterococcus faecium & 17 & 2.01 \\
\hline Morganella morganii & 17 & 2.01 \\
\hline Finegoldia magna & 12 & 1.42 \\
\hline Enterobacter aerogenes & 9 & 1.07 \\
\hline Klebsiella oxytoca & 9 & 1.07 \\
\hline Streptococcus mitis & 9 & 1.07 \\
\hline Stenotrophomonas maltophilia & 7 & 0.83 \\
\hline Veillonella spp. & 6 & 0.71 \\
\hline Anaerococcus prevotii & 5 & 0.59 \\
\hline Citrobacter freundii & 5 & 0.59 \\
\hline Peptoniphilus asaccharolyticus & 5 & 0.59 \\
\hline Streptococcus dysgalactiae & 5 & 0.59 \\
\hline Bacteroides fragilis & 4 & 0.47 \\
\hline Citrobacter braakii & 4 & 0.47 \\
\hline Proteus vulgaris & 4 & 0.47 \\
\hline Proteus penneri & 4 & 0.47 \\
\hline Streptococcus pyogenes & 4 & 0.47 \\
\hline Streptococcus constellatus & 4 & 0.47 \\
\hline Clostridium sporogenes & 3 & 0.36 \\
\hline Prevotella spp. & 3 & 0.36 \\
\hline Providencia rettgeri & 3 & 0.36 \\
\hline Serratia marcescens & 3 & 0.36 \\
\hline Citrobacter koseri & 3 & 0.36 \\
\hline Acinetobacter lwoffii & 2 & 0.24 \\
\hline Actinomyces naeslundii & 2 & 0.24 \\
\hline Bacteroides distasonis & 2 & 0.24 \\
\hline Bifidobacterium spp. & 2 & 0.24 \\
\hline Citrobacter youngae & 2 & 0.24 \\
\hline Clostridium innocuum & 2 & 0.24 \\
\hline Clostridium novyi & 2 & 0.24 \\
\hline Corynebacterium striatum & 2 & 0.24 \\
\hline Lactobacillus fermentum & 2 & 0.24 \\
\hline Peptostreptococcus spp. & 2 & 0.24 \\
\hline Prevotella melaninogenica & 2 & 0.24 \\
\hline Propionibacterium acnes & 2 & 0.24 \\
\hline Staphylococcus epidermidis & 2 & 0.24 \\
\hline Alcaligenes denitrificans & 1 & 0.12 \\
\hline Bacteroides uniformis & 1 & 0.12 \\
\hline
\end{tabular}

TABle 1: Continued.

\begin{tabular}{lcc}
\hline & Number of isolates & Percent \\
\hline Clostridium subterminale & 1 & 0.12 \\
Clostridium perfringens & 1 & 0.12 \\
Clostridium hastiforme & 1 & 0.12 \\
Corynebacterium amycolatum & 1 & 0.12 \\
Fusobacterium necrophorum & 1 & 0.12 \\
Gemella morbillorum & 1 & 0.12 \\
Lactobacillus paracasei & 1 & 0.12 \\
Pseudomonas oleovorans & 1 & 0.12 \\
Peptostreptococcus anaerobius & 1 & 0.12 \\
Peptostreptococcus prevotii & 1 & 0.12 \\
Peptostreptococcus tetradius & 1 & 0.12 \\
Prevotella loescheii & 1 & 0.12 \\
Prevotella oris & 1 & 0.12 \\
Providencia stuartii & 1 & 0.12 \\
Staphylococcus hominis & 1 & 0.12 \\
Staphylococcus lugdunensis & 1 & 0.12 \\
Staphylococcus simulans & 1 & 0.12 \\
Streptococcus spp. & 1 & 0.12 \\
\hline
\end{tabular}

\section{Material and Methods}

The analysis included 291 patients hospitalized in the Angiology Clinic in the years 2016-2019 with a diagnosis of DFS with infection. According to IDSA guidelines, infection was diagnosed if two symptoms of inflammation (erythema, warmth, tenderness, pain, and induration) or purulent secretion were found [3]. In all the patients, a microbiological culture was performed using properly obtained material from ulceration (wound). The material was taken after rinsing the wound with $0.9 \% \mathrm{NaCl}$ solution from the most profound obtainable tissues; tissue aspirates and material collected during surgical debridement or amputation were also cultured. The disk-diffusion method with paper discs impregnated with antibiotics at a specific concentration was used to determine the susceptibility of microorganisms to antibiotics and chemotherapeutics. The detailed protocol of the testing can be found in the literature [4]. The size of the inhibition zone around the disc indicates the susceptibility of the particular bacterial strain to the analyzed antibacterial agent.

The patients were classified as having ischemic DFS (if peripheral arterial disease (PAD) was present, irrespective of the presence of polyneuropathy) or as having nonischemic DFS (if peripheral arterial disease was absent and there was polyneuropathy). Polyneuropathy was diagnosed based on the patient's history and the results of physical examination including assessment of temperature (using Tip-Therm), touch $(10 \mathrm{~g}$ monofilament), pinprick, vibration $(128 \mathrm{~Hz}$ tuning fork), and reflexes (Achilles tendon reflex and knee reflex) [5]. If the results of neurological examination were not conclusive, electromyography and electroneurography were performed. The diagnosis of peripheral arterial disease (PAD) was established according to the current guidelines by means of accessory examinations, i.e., ankle-brachial 
TABLE 2: Number of particular bacterial isolates in all patients with nonischemic diabetic foot syndrome.

\begin{tabular}{|c|c|c|}
\hline & $\begin{array}{c}\text { Number of } \\
\text { isolates }\end{array}$ & Percent \\
\hline Staphylococcus aureus MSS & 88 & $14.47 \%$ \\
\hline Enterococcus faecalis & 48 & $7.89 \%$ \\
\hline Pseudomonas aeruginosa & 41 & $6.74 \%$ \\
\hline Enterobacter cloacae & 33 & $5.42 \%$ \\
\hline Escherichia coli & 32 & $5.26 \%$ \\
\hline Staphylococcus aureus MRSA, MLSB & 25 & $4.11 \%$ \\
\hline Acinetobacter baumannii MDR & 24 & $3.95 \%$ \\
\hline Klebsiella pneumoniae & 24 & $3.95 \%$ \\
\hline Enterobacter cloacae ESBL & 20 & $3.29 \%$ \\
\hline Proteus mirabilis & 17 & $2.80 \%$ \\
\hline Staphylococcus aureus MSS, MLSB & 17 & $2.80 \%$ \\
\hline Proteus spp. & 15 & $2.47 \%$ \\
\hline Enterococcus faecalis HLAR & 14 & $2.30 \%$ \\
\hline Klebsiella pneumoniae ESBL & 13 & $2.14 \%$ \\
\hline Streptococcus agalactiae & 12 & $1.97 \%$ \\
\hline Staphylococcus aureus MRSA & 12 & $1.97 \%$ \\
\hline Morganella morganii & 11 & $1.81 \%$ \\
\hline Acinetobacter baumannii & 10 & $1.64 \%$ \\
\hline Finegoldia magna & 10 & $1.64 \%$ \\
\hline Klebsiella oxytoca & 8 & $1.32 \%$ \\
\hline Enterobacter aerogenes & 8 & $1.32 \%$ \\
\hline Streptococcus mitis & 6 & $0.99 \%$ \\
\hline Stenotrophomonas maltophilia & 5 & $0.82 \%$ \\
\hline Peptoniphilus asaccharolyticus & 5 & $0.82 \%$ \\
\hline Enterococcus faecium HLAR & 5 & $0.82 \%$ \\
\hline Enterococcus faecium & 5 & $0.82 \%$ \\
\hline Veillonella spp. & 4 & $0.66 \%$ \\
\hline Proteus penneri & 4 & $0.66 \%$ \\
\hline Escherichia coli ESBL & 4 & $0.66 \%$ \\
\hline Citrobacter freundii & 4 & $0.66 \%$ \\
\hline Anaerococcus prevotii & 4 & $0.66 \%$ \\
\hline Bacteroides fragilis & 4 & $0.66 \%$ \\
\hline Streptococcus agalactiae MLSB & 3 & $0.49 \%$ \\
\hline Serratia marcescens & 3 & $0.49 \%$ \\
\hline Providencia rettgeri & 3 & $0.49 \%$ \\
\hline Pseudomonas aeruginosa $\mathrm{MDR}, \mathrm{MBL}$ & 3 & $0.49 \%$ \\
\hline Pseudomonas aeruginosa MDR & 3 & $0.49 \%$ \\
\hline Streptococcus constellatus & 2 & $0.33 \%$ \\
\hline Proteus vulgaris & 2 & $0.33 \%$ \\
\hline Propionibacterium acnes & 2 & $0.33 \%$ \\
\hline Prevotella spp. & 2 & $0.33 \%$ \\
\hline Prevotella melaninogenica & 2 & $0.33 \%$ \\
\hline Peptostreptococcus spp. & 2 & $0.33 \%$ \\
\hline Morganella morganii ESBL & 2 & $0.33 \%$ \\
\hline Enterococcus faecium HLAR, VRE & 2 & $0.33 \%$ \\
\hline Corynebacterium striatum & 2 & $0.33 \%$ \\
\hline Clostridium novyi & 2 & $0.33 \%$ \\
\hline
\end{tabular}

TABLe 2: Continued.

\begin{tabular}{|c|c|c|}
\hline & $\begin{array}{c}\text { Number of } \\
\text { isolates }\end{array}$ & Percent \\
\hline Citrobacter braakii AMP C & 2 & $0.33 \%$ \\
\hline Bacteroides distasonis & 2 & $0.33 \%$ \\
\hline Acinetobacter lwoffii & 2 & $0.33 \%$ \\
\hline Citrobacter braakii & 2 & $0.33 \%$ \\
\hline Streptococcus pyogenes & 1 & $0.16 \%$ \\
\hline Staphylococcus simulans & 1 & $0.16 \%$ \\
\hline $\begin{array}{l}\text { Staphylococcus lugdunensis MLSB, } \\
\text { MRS }\end{array}$ & 1 & $0.16 \%$ \\
\hline Staphylococcus epidermidis MRS & 1 & $0.16 \%$ \\
\hline Staphylococcus epidermidis & 1 & $0.16 \%$ \\
\hline Pseudomonas oleovorans & 1 & $0.16 \%$ \\
\hline Proteus mirabilis ESBL & 1 & $0.16 \%$ \\
\hline Prevotella oris & 1 & $0.16 \%$ \\
\hline Prevotella loescheii & 1 & $0.16 \%$ \\
\hline Peptostreptococcus tetradius & 1 & $0.16 \%$ \\
\hline Peptostreptococcus prevotii & 1 & $0.16 \%$ \\
\hline Peptostreptococcus anaerobius & 1 & $0.16 \%$ \\
\hline Pseudomonas aeruginosa MBL & 1 & $0.16 \%$ \\
\hline Lactobacillus paracasei & 1 & $0.16 \%$ \\
\hline Lactobacillus fermentum & 1 & $0.16 \%$ \\
\hline Fusobacterium necrophorum & 1 & $0.16 \%$ \\
\hline Enterococcus faecalis HLAR, VRE & 1 & $0.16 \%$ \\
\hline Enterobacter cloacae AMP C, ESBL & 1 & $0.16 \%$ \\
\hline Enterobacter cloacae AMP C & 1 & $0.16 \%$ \\
\hline Corynebacterium amycolatum & 1 & $0.16 \%$ \\
\hline Clostridium perfringens & 1 & $0.16 \%$ \\
\hline Clostridium subterminale & 1 & $0.16 \%$ \\
\hline Clostridium sporogenes & 1 & $0.16 \%$ \\
\hline Clostridium innocuum & 1 & $0.16 \%$ \\
\hline Clostridium hastiforme & 1 & $0.16 \%$ \\
\hline Citrobacter youngae AMP C & 1 & $0.16 \%$ \\
\hline Citrobacter youngae & 1 & $0.16 \%$ \\
\hline Citrobacter koseri & 1 & $0.16 \%$ \\
\hline Citrobacter freundii ESBL & 1 & $0.16 \%$ \\
\hline Bifidobacterium spp. & 1 & $0.16 \%$ \\
\hline Bacteroides uniformis & 1 & $0.16 \%$ \\
\hline Alcaligenes denitrificans & 1 & $0.16 \%$ \\
\hline Staphylococcus hominis & 1 & $0.16 \%$ \\
\hline
\end{tabular}

Abbreviations: MSS: methicillin-susceptible Staphylococcus; MRSA: methicillin-resistant Staphylococcus aureus; MLSB: macrolide-lincosamidestreptogramin B resistance; MDR: multiple drug resistant; ESBL: extended spectrum beta-lactamase; HLAR: high-level aminoglycoside resistance; MBL: metallo-beta-lactamase; VRE: vancomycin-resistant enterococci; AMP C: AmpC beta-lactamases.

index (ABI), Doppler ultrasound of the extremity vessels, computed tomography angiography, angio-MRI, or arteriography [6].

The obtained results were analyzed statistically. In the case of normally distributed variables (identified by the Shapiro-Wilk test) and homogeneity of variance (confirmed 
TABLE 3: Number of particular bacterial isolates in all patients with ischemic diabetic foot syndrome.

\begin{tabular}{|c|c|c|}
\hline & Number of isolates & Percent \\
\hline Staphylococcus aureus MSS & 38 & $16.10 \%$ \\
\hline Enterococcus faecalis & 26 & $11.02 \%$ \\
\hline Acinetobacter baumannii MDR & 14 & $5.93 \%$ \\
\hline Proteus mirabilis & 13 & $5.51 \%$ \\
\hline Staphylococcus aureus MLSB & 13 & $5.51 \%$ \\
\hline Staphylococcus aureus MRSA, MLSB & 11 & $4.66 \%$ \\
\hline Pseudomonas aeruginosa & 10 & $4.24 \%$ \\
\hline Enterobacter cloacae & 9 & $3.81 \%$ \\
\hline Klebsiella pneumoniae & 9 & $3.81 \%$ \\
\hline Escherichia coli & 8 & $3.39 \%$ \\
\hline Enterococcus faecalis HLAR & 7 & $2.97 \%$ \\
\hline Staphylococcus aureus MRSA & 7 & $2.97 \%$ \\
\hline Streptococcus agalactiae & 7 & $2.97 \%$ \\
\hline Acinetobacter baumannii & 6 & $2.54 \%$ \\
\hline Morganella morganii & 4 & $1.69 \%$ \\
\hline Proteus spp. & 4 & $1.69 \%$ \\
\hline Streptococcus dysgalactiae & 4 & $1.69 \%$ \\
\hline Enterococcus faecium & 3 & $1.27 \%$ \\
\hline Streptococcus mitis & 3 & $1.27 \%$ \\
\hline Streptococcus pyogenes & 3 & $1.27 \%$ \\
\hline Actinomyces naeslundii & 2 & $0.85 \%$ \\
\hline Citrobacter koseri & 2 & $0.85 \%$ \\
\hline Clostridium sporogenes & 2 & $0.85 \%$ \\
\hline Finegoldia magna & 2 & $0.85 \%$ \\
\hline Klebsiella pneumoniae ESBL & 2 & $0.85 \%$ \\
\hline Proteus vulgaris & 2 & $0.85 \%$ \\
\hline Stenotrophomonas maltophilia & 2 & $0.85 \%$ \\
\hline Streptococcus agalactiae MLSB & 2 & $0.85 \%$ \\
\hline Streptococcus constellatus & 2 & $0.85 \%$ \\
\hline Veillonella spp. & 2 & $0.85 \%$ \\
\hline Anaerococcus prevotii & 1 & $0.42 \%$ \\
\hline Bifidobacterium spp. & 1 & $0.42 \%$ \\
\hline Clostridium innocuum & 1 & $0.42 \%$ \\
\hline Enterobacter cloacae AMP C, ESBL & 1 & $0.42 \%$ \\
\hline Enterobacter cloacae ESBL & 1 & $0.42 \%$ \\
\hline Enterococcus faecium HLAR & 1 & $0.42 \%$ \\
\hline Enterococcus faecium HLAR, VRE & 1 & $0.42 \%$ \\
\hline Enterobacter aerogenes & 1 & $0.42 \%$ \\
\hline Gemella morbillorum & 1 & $0.42 \%$ \\
\hline Klebsiella oxytoca & 1 & $0.42 \%$ \\
\hline Klebsiella pneumoniae MBL MDR & 1 & $0.42 \%$ \\
\hline Klebsiella pneumoniae MDR & 1 & $0.42 \%$ \\
\hline Lactobacillus fermentum & 1 & $0.42 \%$ \\
\hline Prevotella spp. & 1 & $0.42 \%$ \\
\hline Providencia stuartii ESBL, AMP C & 1 & $0.42 \%$ \\
\hline Streptococcus dysgalactiae MLSB & 1 & $0.42 \%$ \\
\hline Streptococcus spp. & 1 & $0.42 \%$ \\
\hline
\end{tabular}

Abbreviations: MSS: methicillin-susceptible Staphylococcus; MDR: multiple drug resistant; MLSB: macrolide-lincosamide-streptogramin B resistance; MRSA: methicillin-resistant Staphylococcus aureus; HLAR: high-level aminoglycoside resistance; ESBL: extended spectrum beta-lactamase; AMP C: AmpC beta-lactamases; VRE: vancomycin-resistant enterococci; MBL: metallo-beta-lactamase. by the Levene test), differences between groups were determined using Student's $t$-test. Alternatively, in the case of nonnormal distributed variables, the Mann-Whitney $U$ test was applied. Intergroup differences in the percentage distributions of dichotomous variables were analyzed with Pearson's $\chi^{2}$ test. $p$ value $<0.05$ was considered statistically significant. All calculations were conducted with the Statistica version 13.3 (TIBCO Software Inc.).

\section{Results}

The analysis included 844 bacterial strains obtained from 291 patients with DFS (183 males and 108 females) at the mean age of $65.38( \pm 11.80)$ years. One bacteria strain was obtained only in 99 people (34.02\%), 2 strains in 66 people (22.68\%), 3 strains in 44 people (15.12\%), and more than 3 strains in 82 cases $(28.18 \%)$. Gram-positive $($ no $=426,50.47 \%)$ and Gram-negative strains (no $=418,49.53 \%$ ) occurred almost equally often. 52 strains of anaerobic bacteria (6.16\%) were isolated.

The most common isolated bacteria were Staphylococcus aureus (no $=211,25.00 \%$ ), Enterococcus faecalis (no $=96$, $11.37 \%)$, Enterobacter cloacae (no $=66,7.82 \%)$, Pseudomonas aeruginosa (no $=58,6.87 \%)$, and Acinetobacter baumannii $($ no $=54,6.40 \%)$. All isolated strains are presented in Table 1, in patients with nonischemic DFS in Table 2, and in patients with ischemic DFS in Table 3. As many as 162 isolated strains (19.19\%) were found to have at least one resistance mechanism; the most important types of resistance and its percentage shared in particular bacteria are presented in Table 4.

Relationships between the results of laboratory test and the etiological factor were nonsignificant, with the exception of the percentage of glycated hemoglobin Alc (HbAlc). $\mathrm{HbA1c}$ was higher in infections with $E$. faecalis than in other bacteria ( 9.26 vs. $8.68 \%, p=0.02245$ ); a similar relationship was found for A. baumannii (9.31 vs. $8.72 \%, p=0.04768$ ). On the other hand, in people with E. cloacae infection, a lower level of $\mathrm{HbA1c}$ was observed compared to other bacteria ( 8.13 vs. $8.80 \%, p=0.01718)$; a similar trend was shown regarding $P$. aeruginosa infection (7.96 vs. $8.81 \%, p=$ $0.00383)$.

369 isolates $(43.72 \%)$ were obtained from people with neuropathic-ischemic DFS, 239 (28.32\%) from ischemic DFS, and 236 (27.96\%) from neuropathic DFS. In patients with PAD, Gram-negative species were isolated more commonly than in people with normal extremity perfusion (53.18 vs. $40.25 \%, p=0.00077$ ) (Figure 1), whilst anaerobes were cultured equally often in both groups. In patients with $\mathrm{PAD}$, E. cloacae was isolated almost twice as often as in patients with normal extremity perfusion (8.88 vs. $4.66 \%)$; in other cases, there were no significant differences in regard to main etiological factors.

Carbapenems, especially meropenem, tigecycline, and aminoglycosides turned out to be the most useful antibiotics in monotherapy followed by $4^{\text {th }}$ and $5^{\text {th }}$ generations of cephalosporins and penicillins with beta-lactamase inhibitors. Their empiric usefulness, however, partially depends on the type of DFS (ischemic or nonischemic). This relationship is 
TABLE 4: Occurrence of particular resistance mechanisms in all analyzed bacterial strains.

\begin{tabular}{lc}
\hline Species and resistance mechanism & $\begin{array}{c}\text { Percentage of } \\
\text { isolated strains } \\
\text { with the particular } \\
\text { mechanism }\end{array}$ \\
\hline Acinetobacter baumannii MDR & $70.37 \%$ \\
Staphylococcus aureus MRSA & $9.00 \%$ \\
Staphylococcus aureus MLSB & $13.74 \%$ \\
Staphylococcus aureus MRSA, MLSB & $17.06 \%$ \\
Enterococcus faecalis HLAR & $21.88 \%$ \\
Enterococcus faecalis HLAR, VRE (no = 4) & $4.17 \%$ \\
Enterococcus faecium HLAR, VRE (no = 3) & $17.64 \%$ \\
Enterobacter cloacae ESBL & $32.31 \%$ \\
Enterobacter cloacae ESBL, AMP C (no = 2) & $3.08 \%$ \\
Klebsiella pneumoniae ESBL & $30 \%$ \\
Klebsiella pneumoniae MBL, MDR (no =1) & $0.50 \%$ \\
Escherichia coli ESBL & $9.10 \%$ \\
Proteus mirabilis ESBL (no = 1) & $3.20 \%$ \\
Morganella morganii ESBL (no = 2) & $11.76 \%$ \\
Pseudomonas aeruginosa MDR, MBL (no = 3) & $5.17 \%$ \\
\hline MDR: min
\end{tabular}

MDR: multiple drug resistant; MRSA: methicillin-resistant Staphylococcus aureus; MLSB: macrolide-lincosamide-streptogramin B resistance; HLAR: high-level aminoglycoside resistance; VRE: vancomycin-resistant enterococci; ESBL: extended spectrum beta-lactamase; AMP C: AmpC beta-lactamases; MBL: metallo-beta-lactamase.

particularly pronounced in the case of amoxicillin with clavulanate, $1^{\text {st }}$-generation cephalosporins, and glyco- and lipopeptides (more useful in the neuropathic DFS), as well as ceftazidime, aztreonam, levofloxacin, moxifloxacin, and colistin (more useful in DFS). The differences in the utility of antibacterial agents in particular types of DFS are presented in Table 5. Noteworthily, low sensitivity of bacterial strains to metronidazole, macrolides, and clindamycin was found in all patients.

Patients included in the study were hospitalized, and according to the current guidelines in such circumstance, the empiric treatment should consist of at least two antibacterial agents. The most common treatment regimens cited in the literature and their usefulness in patients with ischemic and nonischemic DFS were analyzed (Table 6). The combination of amoxicillin/clavulanate with vancomycin turned out to be less useful by almost half in people with nonischemic DFS than in patients with coexistent PAD (a similar relationship was also observed for piperacillin/tazobactam and vancomycin); the opposite correlation was found for the combination of carbapenems with vancomycin. Fluoroquinolones together with clindamycin, ceftazidime, and metronidazole showed unacceptably low utility, and the treatment regimen based on ceftazidime with clindamycin was only suitable in $52 \%$.

An attempt was made to establish acceptable and applicable regimens of empiric antibiotic therapy, excluding antibiotics with serious side effects (e.g., colistin and vancomycin), used only in the case of resistance to other drugs and after receiving the results of microbiological culture (e.g., carbapenems) and expensive, hardly available antibiotics (e.g., $4^{\text {th }}$ - and $5^{\text {th }}$-generation cephalosporins, linezolid, and tigecycline). The results of the analysis are presented in Table 6 .

\section{Discussion}

As in our previous study [7], Gram-positive and Gramnegative strains were isolated with almost the same frequency. It is considered that infections with Gram-positive bacteria are more common in Western communities, whilst Gram-negative bacteria are more common in Eastern communities [8]. However, this explanation seems to be unsatisfactory with respect to the high percentage of Gram-negative bacteria observed in our group. A possible explanation is that the analyzed population included hospitalized patients, previously treated in various hospital wards, with more severe infection involving more than one bacterial strain, commonly with coexistent PAD. Because the Department of Angiology is a part of the general health system, the study group most probably represents the population of hospitalized patients in general.

Despite a similar distribution of Gram-positive and Gram-negative species, the prevalence of particular bacteria is different compared to our study from 2014. The most common isolate in the aforementioned study had been Enterococcus faecalis (16.08\%), which in the present analysis has taken the second position (11.37\%), as nearly one-fourth of all infections are caused by Staphylococcus aureus that predominate in the study. Enterobacter cloacae was at third place, which may be alarming because of the high tendency of this species to produce mechanisms of antibiotic resistance [9]. Pseudomonas aeruginosa continues to be the fourth most frequently isolated pathogen among patients with DFS. The fifth most often isolated pathogen is Acinetobacter baumannii (6.40\% compared to $2.01 \%$ in 2014$)$, which is concerning due to the evidently hospital origin of this strain and its significant resistance to antibiotics [10]. Noteworthily, the low frequency of Streptococcus bacteria can partially result from a use of beta-lactam antibiotics as first-line drugs in the general population.

The common occurrence of strains resistant to antibiotics is especially problematic, as many as $20 \%$ isolates have at least one resistance mechanism, and the MDR strain accounted for $70 \%$ of isolated Acinetobacter baumannii (distribution similar to observed in other centers [11]). The resistance of one-fifth of all bacteria in the population with DFS has serious consequences for treatment effectiveness, since standard empiric with antibacterial agents cannot be successful in more than $80 \%$ of cases.

In the present analysis, the susceptibility of bacteria to antibiotics was analyzed in relation to algorithms presented in available guidelines $[12,13]$. Although monotherapy with meropenem covers $82 \%$ of isolated strains, in case of other antibacterial agents, this proportion does not exceed $75 \%$ (tigecycline) and 68\% (aminoglycosides). Penicillins with beta-lactamase inhibitor were suitable in more than $50 \%$ of cases, similar to cephalosporins of $4^{\text {th }}$ generation and $5^{\text {th }}$ generation (with exception of ceftalozane). Some $3^{\text {rd }}$-generation cephalosporins (ceftriaxone, cefotaxime) were useful in less than $50 \%$ of isolates. 


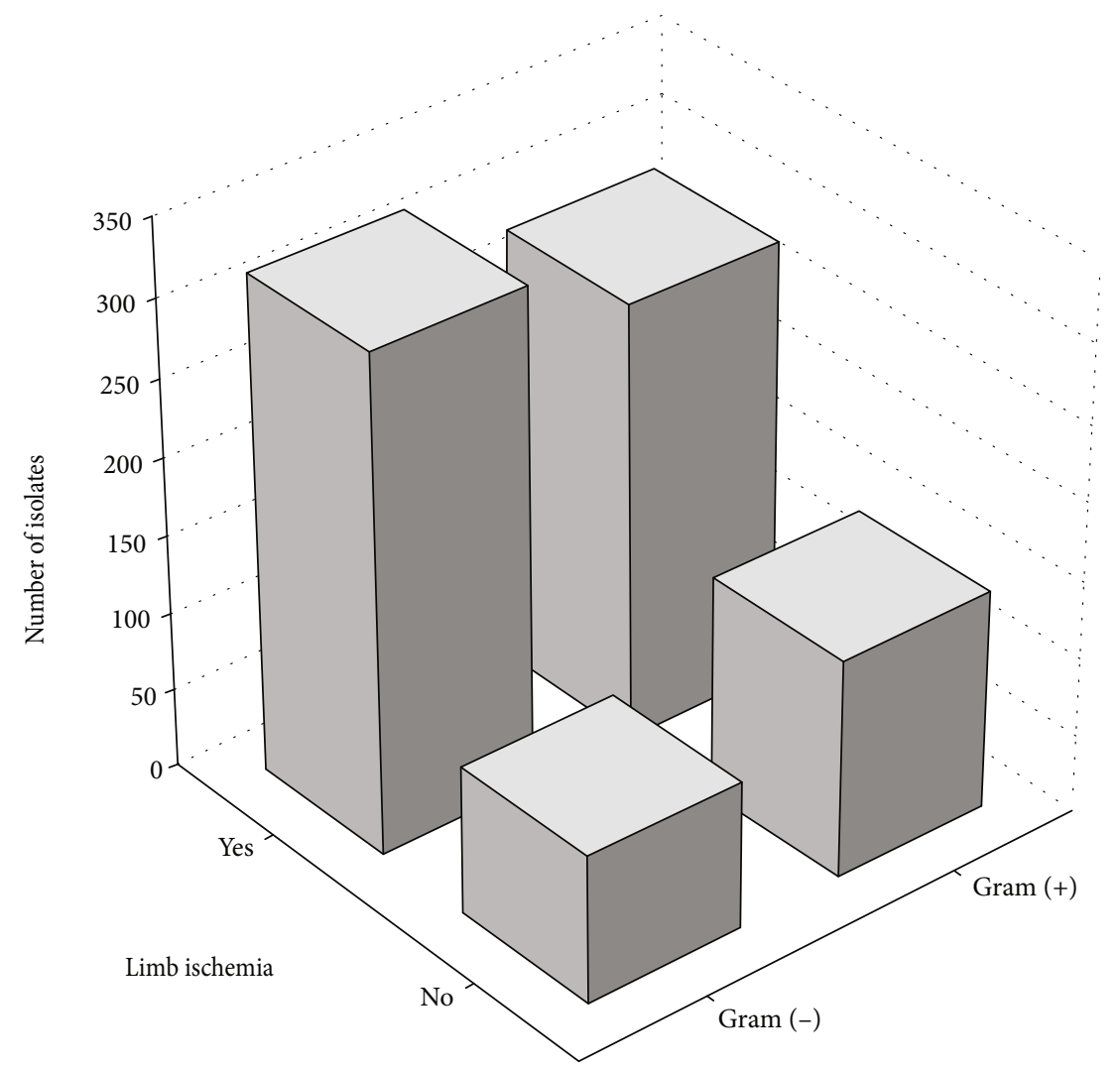

FIGURE 1: The proportion of Gram-positive and Gram-negative bacteria in patients with and without coexistent peripheral arterial disease (extremity ischemia).

The guidelines in severe infections usually recommend intravenous ciprofloxacin with clindamycin (only $46 \%$ accuracy in our study), amoxicillin/clavulanate with vancomycin (62\%), piperacillin/tazobactam with vancomycin (87\%), amoxicillin/clavulanate with cotrimoxazole (73\%), ciprofloxacin with linezolid (64\%), and moxifloxacin with linezolid (59\%). In the present study, a high proportion of susceptible bacteria have been found in relation to amoxicillin/clavulanate with amikacin $(83 \%)$ and ceftriaxone with amikacin (77\%); more available and cheaper cefuroxime with amikacin has the accuracy of $76 \%$. We also proved low usefulness of some groups of drugs in DFS, i.e., fluoroquinolones and macrolides. Despite the special role of clindamycin and metronidazole in anaerobic infection, their accuracy in this purpose is limited $(58 \%$ for clindamycin and $54 \%$ for metronidazole), compared to amoxicillin/clavulanate (90\%).

$\mathrm{PAD}$ is an important factor affecting prognosis in patients with DFS. Various analyses have shown different rates of PAD in people with diabetes, ranging from $49 \%$ in the EURODIALE study [14] to about $60 \%$ in analysis involving smaller populations [15]; however, some researchers postulate that this proportion may be higher [16]. In the analyzed population, the incidence of PAD was $72.02 \%$ (including patients with ischemic diabetic foot without neuropathy and mixed, ischemic-neuropathic DFS). In metaanalysis involving over 50,000 patients with DFS, the presence of PAD was associated with two times higher risk of major limb amputation [17]. Nevertheless, data on diversity of particular pathogens and their susceptibility to antibiotics in patients with diabetes and PAS is scarce.

In the present study, it was found that Gram-negative bacteria occurs about $1 / 4$ more frequently in ischemic compared to nonischemic DFS, which may result in a different sensitivity to commonly used groups of antibacterial agents. Moreover, it was shown that bacterial strains isolated from ischemic feet are more resistant to the most commonly used groups of antibiotics, i.e., penicillins (including combinations with their inhibitors), cephalosporins (except for the 4th and 5 th generations), glycopeptides, and linezolid. Although the shift towards Gram-negative bacteria is well known in the literature for extremity ischemic ulcers [18], it is uncommonly taken into consideration in the context of DFS.

We can also speculate that differences in isolate patterns between ischemic and nonischemic DFS are not only a consequence of the higher morbidity and more frequent contact with health care but also may result from different local environments of neuropathic and ischemic ulcers. Indeed, in a typical diabetic foot, the infection is driven by neuropathy and its sequelae, hyperglycemia, and probably dysfunction of the immune system [19]. Ischemia may additionally favor the development of Gram-negative bacteria (e.g., there are reports of increased invasiveness of Gram-negative bacteria, e.g., in people with anemia) [20].

There are some limitations in our analysis. Undoubtedly, the effectiveness of a given chemotherapeutic agent is determined by its clinical effect, not by the result of the 
TABLE 5: Susceptibility of bacterial strains to antibiotics in the entire study group, in people with or without PAD (peripheral arterial disease).

\begin{tabular}{|c|c|c|c|c|}
\hline Antibacterial agent & Susceptibility in all patients & $\begin{array}{l}\text { Susceptibility in patients } \\
\text { with PAD }\end{array}$ & $\begin{array}{c}\text { Susceptibility in patients } \\
\text { without PAD }\end{array}$ & Statistical significance, $p$ \\
\hline \multicolumn{5}{|c|}{ Penicillins and penicillins with beta-lactamase inhibitor } \\
\hline Penicillin G & $23 \%$ & $20 \%$ & $28 \%$ & $p=0.01891$ \\
\hline Ampicillin & $27 \%$ & $26 \%$ & $30 \%$ & $p=0.18143$ \\
\hline Amoxicillin & $26 \%$ & $25 \%$ & $30 \%$ & $p=0.12352$ \\
\hline Amoxicillin with clavulanate & $53 \%$ & $51 \%$ & $61 \%$ & $p=0.00945$ \\
\hline Piperacillin with tazobactam & $57 \%$ & $57 \%$ & $59 \%$ & $p=0.58503$ \\
\hline \multicolumn{5}{|l|}{ Cephalosporins } \\
\hline \multicolumn{5}{|l|}{ Cephalexin } \\
\hline $\begin{array}{l}\text { Cephadroxyl } \\
\text { Cefazolin }\end{array}$ & $26 \%$ & $24 \%$ & $31 \%$ & $p=0.03479$ \\
\hline \multicolumn{5}{|l|}{ Cefaclor } \\
\hline Cefuroxime & $35 \%$ & $33 \%$ & $39 \%$ & $p=0.16400$ \\
\hline Ceftazidime & $30 \%$ & $33 \%$ & $24 \%$ & $p=0.01237$ \\
\hline Cefotaxime & $48 \%$ & $47 \%$ & $50 \%$ & $p=0.38042$ \\
\hline Ceftriaxone & $49 \%$ & $47 \%$ & $51 \%$ & $p=0.31700$ \\
\hline Cefixime & $31 \%$ & $32 \%$ & $27 \%$ & $p=0.17967$ \\
\hline Ceftybuten & $30 \%$ & $32 \%$ & $27 \%$ & $p=0.19485$ \\
\hline Cefepime & $62 \%$ & $62 \%$ & $64 \%$ & $p=0.58677$ \\
\hline Ceftalozane & $37 \%$ & $39 \%$ & $32 \%$ & $p=0.06028$ \\
\hline Ceftaroline & $58 \%$ & $56 \%$ & $64 \%$ & $p=0.05635$ \\
\hline \multicolumn{5}{|l|}{ Monobactams } \\
\hline Aztreonam & $29 \%$ & $31 \%$ & $22 \%$ & $p=0.00712$ \\
\hline \multicolumn{5}{|l|}{ Carbapenems } \\
\hline Meropenem & $82 \%$ & $83 \%$ & $80 \%$ & $p=0.32769$ \\
\hline Imipenem with cilastatin & $79 \%$ & $80 \%$ & $76 \%$ & $p=0.12597$ \\
\hline Ertapenem & $79 \%$ & $79 \%$ & $81 \%$ & $p=0.41590$ \\
\hline \multicolumn{5}{|l|}{ Glycopeptides } \\
\hline Vancomycin & $50 \%$ & $46 \%$ & $58 \%$ & $p=0.00197$ \\
\hline Teicoplanin & $50 \%$ & $46 \%$ & $59 \%$ & $p=0.00135$ \\
\hline Dalbavancin & $50 \%$ & $47 \%$ & $59 \%$ & $p=0.00155$ \\
\hline \multicolumn{5}{|l|}{ Lipopeptides } \\
\hline Daptomycin & $48 \%$ & $45 \%$ & $57 \%$ & $p=0.00199$ \\
\hline \multicolumn{5}{|l|}{ Aminoglycosides } \\
\hline Gentamicin & $65 \%$ & $67 \%$ & $63 \%$ & $p=0.28476$ \\
\hline Amikacin & $65 \%$ & $66 \%$ & $65 \%$ & $p=0.86581$ \\
\hline Tobramycin & $68 \%$ & $68 \%$ & $69 \%$ & $p=0.87520$ \\
\hline \multicolumn{5}{|l|}{ Tetracyclines } \\
\hline Doxycycline & $40 \%$ & $38 \%$ & $44 \%$ & $p=0.08849$ \\
\hline \multicolumn{5}{|l|}{ Glycylcycline } \\
\hline Tigecycline & $75 \%$ & $53 \%$ & $80 \%$ & $p=0.05511$ \\
\hline \multicolumn{5}{|l|}{ Macrolides } \\
\hline Erythromycin & $9 \%$ & $9 \%$ & $11 \%$ & $p=0.34070$ \\
\hline $\begin{array}{l}\text { Clarithromycin } \\
\text { Azithromycin } \\
\text { Lincosamides }\end{array}$ & $9 \%$ & $8 \%$ & $10 \%$ & $p=0.46091$ \\
\hline
\end{tabular}


TABle 5: Continued.

\begin{tabular}{|c|c|c|c|c|}
\hline Antibacterial agent & Susceptibility in all patients & $\begin{array}{l}\text { Susceptibility in patients } \\
\text { with PAD }\end{array}$ & $\begin{array}{c}\text { Susceptibility in patients } \\
\text { without PAD }\end{array}$ & Statistical significance, $p$ \\
\hline Clindamycin & $24 \%$ & $22 \%$ & $28 \%$ & $p=0.07191$ \\
\hline \multicolumn{5}{|l|}{ Oxazolidinones } \\
\hline Linezolid & $47 \%$ & $43 \%$ & $56 \%$ & $p=0.00087$ \\
\hline \multicolumn{5}{|l|}{ Fluoroquinolones } \\
\hline Ciprofloxacin & $35 \%$ & $36 \%$ & $29 \%$ & $p=0.10831$ \\
\hline Levofloxacin & $37 \%$ & $39 \%$ & $29 \%$ & $p=0.01410$ \\
\hline Moxifloxacin & $31 \%$ & $34 \%$ & $24 \%$ & $p=0.02502$ \\
\hline \multicolumn{5}{|l|}{ Sulfonamides } \\
\hline Cotrimoxazole & $45 \%$ & $45 \%$ & $46 \%$ & $p=0.78042$ \\
\hline \multicolumn{5}{|l|}{ Nitroimidazoles } \\
\hline Metronidazole & $4 \%$ & $5 \%$ & $2 \%$ & $p=0.02121$ \\
\hline \multicolumn{5}{|l|}{ Polymyxins } \\
\hline Colistin & $34 \%$ & $38 \%$ & $26 \%$ & $p=0.00155$ \\
\hline
\end{tabular}

TABLE 6: Susceptibility of isolates to the most commonly recommended combinations of antibacterial agents in the literature in patients with and without peripheral arterial disease $(\mathrm{PAD})$.

\begin{tabular}{lcccc}
\hline Antibacterial agents & $\begin{array}{c}\text { Susceptibility in } \\
\text { all patients }\end{array}$ & $\begin{array}{c}\text { Susceptibility in } \\
\text { patients with PAD }\end{array}$ & $\begin{array}{c}\text { Susceptibility in } \\
\text { patients without PAD }\end{array}$ & Statistical significance, $p$ \\
\hline Ciprofloxacin with clindamycin & $46 \%$ & $45 \%$ & $46 \%$ & $p=0.90248$ \\
Levofloxacin with clindamycin & $44 \%$ & $45 \%$ & $40 \%$ & $p=0.30085$ \\
Amoxicillin/clavulanate with vancomycin & $62 \%$ & $58 \%$ & $70 \%$ & $p=0.00109$ \\
Piperacillin/tazobactam with vancomycin & $87 \%$ & $85 \%$ & $94 \%$ & $p=0.00050$ \\
Imipenem with vancomycin & $88 \%$ & $89 \%$ & $85 \%$ & $p=0.13444$ \\
Meropenem with vancomycin & $91 \%$ & $91 \%$ & $89 \%$ & $p=0.36788$ \\
Amoxicillin/clavulanate with cotrimoxazole & $73 \%$ & $71 \%$ & $79 \%$ & $p=0.01562$ \\
Ceftazidime with metronidazole & $33 \%$ & $36 \%$ & $24 \%$ & $p=0.00178$ \\
Ceftazidime with clindamycin & $52 \%$ & $53 \%$ & $49 \%$ & $p=0.27473$ \\
Ciprofloxacin with linezolid & $64 \%$ & $61 \%$ & $69 \%$ & $p=0.07458$ \\
Moxifloxacin with linezolid & $59 \%$ & $58 \%$ & $63 \%$ & $p=0.28648$ \\
\hline
\end{tabular}

antibiogram, which comprises only one possible variable. Besides drug availability and compliance, the accuracy of therapy is also determined by other factors not included in the analysis, e.g., tissue penetration of antibacterial agents. For example, it is known that vancomycin is characterized by poor tissue penetration, as opposed to aminoglycosides (moderate penetration) or cotrimoxazole (good penetration) [21]; obviously, in DFS therapy, using drugs with good penetration is preferred. Notwithstanding, the result of antibiogram is always the first step in choosing appropriate therapy and reducing the number of modalities to susceptible medications.

\section{Conclusions}

(1) The most common isolated bacteria in patients with DFS were Staphylococcus aureus, Enterococcus faecalis, Enterobacter cloacae, Pseudomonas aeruginosa, and Acinetobacter baumannii. In patients with PAD and DFS, Gram-negative species were isolated more commonly than in people with neuropathic DFS, whilst anaerobes were cultured equally often in both groups. In patients with PAD, E. cloacae was isolated almost twice as often as in patients without PAD

(2) Including all analyzed patients with DFS, monotherapy with meropenem covers $82 \%$ of isolated strains, but in the case of other antibacterial agents, this proportion does not exceed 75\% (tigecycline) and 68\% (aminoglycosides). Penicillins with beta-lactamase inhibitor were useful in more than $50 \%$ of cases, similar to cephalosporins of $4^{\text {th }}$ generation and $5^{\text {th }}$ generation (with exception of ceftalozane). Some $3^{\text {rd }}$ generation cephalosporins (ceftriaxone, cefotaxime) were suitable in less than $50 \%$ of isolates. Contrarily, clindamycin, metronidazole, and macrolides are definitely less useful and should not be used in the treatment of DFS

(3) Gram-negative bacteria occur about 1/4 more frequently in ischemic compared to nonischemic DFS, which may result in a different sensitivity to commonly used groups 
of antibacterial agents. Moreover, bacterial strains isolated from ischemic feet are more resistant to commonly used antibacterial agents, i.e., penicillins (including penicillins with beta-lactamase inhibitors), cephalosporins (except for the $4^{\text {th }}$ and $5^{\text {th }}$ generations), glycopeptides, and linezolid. In ischemic DFS, merely aztreonam, carbapenems, and fluoroquinolones (a high proportion of resistant strains) appear to be more useful

(4) The most potent combinations of antibacterial agents were carbapenems with vancomycin, piperacillin/tazobactam with vancomycin, ciprofloxacin with linezolid, and moxifloxacin with linezolid. The combinations of fluoroquinolones with clindamycin or ceftazidime with metronidazole showed unacceptably low efficacy. The therapy based on ceftazidime with clindamycin was accurate only in half of the isolates

\section{Data Availability}

Data available on request; please contact Rafał Małecki, email: rafal.malecki@umed.wroc.pl.

\section{Conflicts of Interest}

The authors declare that they have no conflicts of interest.

\section{References}

[1] P. Zhang, J. Lu, Y. Jing, S. Tang, D. Zhu, and Y. Bi, "Global epidemiology of diabetic foot ulceration: a systematic review and meta-analysis," Annals of Medicine, vol. 49, no. 2, pp. 106-116, 2017.

[2] D. F. Bandyk, "The diabetic foot: pathophysiology, evaluation, and treatment," Seminars in Vascular Surgery, vol. 31, no. 2-4, pp. 43-48, 2018.

[3] B. A. Lipsky, A. R. Berendt, P. B. Cornia et al., "2012 Infectious Diseases Society of America clinical practice guideline for the diagnosis and treatment of diabetic foot infectionsa," Clinical Infectious Diseases, vol. 54, no. 12, pp. e132-e173, 2012.

[4] J. Vandepitte, K. Engbaek, P. Rohner, P. Piot, and C. C. Heuck, Basic Laboratory Procedures in Clinical Bacteriology, World Health Organization, Geneva, 2nd edition, 2003.

[5] R. Pop-Busui, A. J. Boulton, E. L. Feldman et al., "Diabetic neuropathy: a position statement by the American Diabetes Association," Diabetes Care, vol. 40, no. 1, pp. 136-154, 2017.

[6] V. Aboyans, J. B. Ricco, M. L. E. L. Bartelink et al., "2017 ESC guidelines on the diagnosis and treatment of peripheral arterial diseases, in collaboration with the European Society for Vascular Surgery (ESVS)," European heart journal, vol. 39, no. 9, pp. 763-816, 2018.

[7] R. Małecki, K. Rosiński, and R. Adamiec, "Etiological factors of infections in diabetic foot syndrome - attempt to define optimal empirical therapy," Advances in Clinical and Experimental Medicine, vol. 23, no. 1, pp. 39-48, 2014.

[8] P. Shanmugam, "The bacteriology of diabetic foot ulcers, with a special reference to multidrug resistant strains," Journal of Clinical and Diagnostic Research, vol. 7, pp. 441-445, 2013.

[9] M. L. Mezzatesta, F. Gona, and S. Stefani, "Enterobacter cloacae complex: clinical impact and emerging antibiotic resistance,” Future Microbiology, vol. 7, no. 7, pp. 887-902, 2012.

[10] C. R. Lee, J. H. Lee, M. Park et al., "Biology of Acinetobacter baumannii: pathogenesis, antibiotic resistance mechanisms, and prospective treatment options," Frontiers in Cellular and Infection Microbiology, vol. 7, p. 55, 2017.

[11] A. Y. Peleg, H. Seifert, and D. L. Paterson, "Acinetobacter baumannii: emergence of a successful pathogen," Clinical Microbiology Reviews, vol. 21, no. 3, pp. 538-582, 2008.

[12] B. A. Lipsky, É. Senneville, Z. G. Abbas et al., "Guidelines on the diagnosis and treatment of foot infection in persons with diabetes (IWGDF 2019 update)," Diabetes/metabolism research and reviews, vol. 36, no. S1, article e3280, 2020.

[13] American Diabetes Association, "11. Microvascular complications and foot Care:Standards of medical care in diabetes2020," Diabetes Care, vol. 43, Supplement 1, pp. S135-S151, 2020.

[14] L. Prompers, M. Huijberts, J. Apelqvist et al., "High prevalence of ischaemia, infection and serious comorbidity in patients with diabetic foot disease in Europe. Baseline results from the Eurodiale study," Diabetologia, vol. 50, no. 1, pp. 18-25, 2007.

[15] M. R. Khammash and K. A. Obeidat, "Prevalence of ischemia in diabetic foot infection," World Journal of Surgery, vol. 27, no. 7, pp. 797-799, 2003.

[16] M. Weck, T. Slesaczeck, H. Rietzsch et al., "Noninvasive management of the diabetic foot with critical limb ischemia: current options and future perspectives," Therapeutic Advances in Endocrinology and Metabolism, vol. 2, no. 6, pp. 247-255, 2011.

[17] J. Y. Shin, S. G. Roh, B. Sharaf, and N. H. Lee, "Risk of major limb amputation in diabetic foot ulcer and accompanying disease: a meta-analysis," Journal of Plastic, Reconstructive \& Aesthetic Surgery, vol. 70, no. 12, pp. 1681-1688, 2017.

[18] F. Jockenhöfer, V. Chapot, M. Stoffels- Weindorf et al., "Bacterial spectrum colonizing chronic leg ulcers: a 10-year comparison from a German wound care center," JDDG: Journal der Deutschen Dermatologischen Gesellschaft, vol. 12, no. 12, pp. 1121-1127, 2014.

[19] M. Delamaire, D. Maugendre, M. Moreno, M. C. Le Goff, H. Allannic, and B. Genetet, "Impaired leucocyte functions in diabetic patients," Diabetic Medicine, vol. 14, no. 1, pp. 29-34, 1997.

[20] K. M. Abuga, J. M. Muriuki, T. N. Williams, and S. H. Atkinson, "How severe anaemia might influence the risk of invasive bacterial infections in African children," International Journal of Molecular Sciences, vol. 21, no. 18, p. 6976, 2020.

[21] N. G. L. Jager, R. M. van Hest, J. Lipman, J. A. Roberts, and M. O. Cotta, "Antibiotic exposure at the site of infection: principles and assessment of tissue penetration," Expert Review of Clinical Pharmacology, vol. 12, no. 7, pp. 623-634, 2019. 